\title{
Blastomycosis Surveillance in 5 States, United States, 1987-2018
}

\author{
Kaitlin Benedict, Suzanne Gibbons-Burgener, Anna Kocharian, Malia Ireland, \\ Laura Rothfeldt, Natalie Christophe, Kimberly Signs, Brendan R. Jackson
}

\begin{abstract}
Medscape ACTIVITY
In support of improving patient care, this activity has been planned and implemented by Medscape, LLC and Emerging Infectious Diseases. Medscape, LLC is jointly accredited by the Accreditation Council for Continuing Medical Education (ACCME), the Accreditation Council for Pharmacy Education (ACPE), and the American Nurses Credentialing Center (ANCC), to provide continuing education for the healthcare team.

Medscape, LLC designates this Journal-based CME activity for a maximum of 1.00 AMA PRA Category 1 Credit(s) ${ }^{\mathrm{TM}}$. Physicians should claim only the credit commensurate with the extent of their participation in the activity.

Successful completion of this CME activity, which includes participation in the evaluation component, enables the participant to earn up to $1.0 \mathrm{MOC}$ points in the American Board of Internal Medicine's (ABIM) Maintenance of Certification (MOC) program. Participants will earn MOC points equivalent to the amount of CME credits claimed for the activity. It is the CME activity provider's responsibility to submit participant completion information to ACCME for the purpose of granting ABIM MOC credit.

All other clinicians completing this activity will be issued a certificate of participation. To participate in this journal CME activity: (1) review the learning objectives and author disclosures; (2) study the education content; (3) take the post-test with a $75 \%$ minimum passing score and complete the evaluation at http://www.medscape.org/journal/eid; and (4) view/print certificate. For CME questions, see page 1255.
\end{abstract}

Release date: March 17, 2021; Expiration date: March 17, 2022

\section{Learning Objectives}

Upon completion of this activity, participants will be able to:

- Describe epidemiologic features of blastomycosis, according to an analysis of combined 19872018 surveillance data from the 5 states where it is reportable

- Determine clinical features of blastomycosis, according to an analysis of combined 1987-2018 surveillance data from the 5 states where it is reportable

- Identify public health and clinical implications of the epidemiologic and clinical features of blastomycosis, according to an analysis of combined 1987-2018 surveillance data from the 5 states where it is reportable

\section{CME Editor}

Amy J. Guinn, BA, MA, Copyeditor, Emerging Infectious Diseases. Disclosure: Amy J. Guinn, BA, MA, has disclosed no relevant financial relationships.

\section{CME Author}

Laurie Barclay, MD, freelance writer and reviewer, Medscape, LLC. Disclosure: Laurie Barclay, MD, has disclosed no relevant financial relationships.

\section{Authors}

Disclosures: Kaitlin Benedict, MPH; Suzanne Gibbons-Burgener, DVM, PhD; Anna Kocharian, MS; Malia Ireland, DVM, MPH; Laura K. Rothfeldt, DVM; Natalie Christophe, MPH; Kimberly Signs, BS, DVM; and Brendan R. Jackson, MD, MPH, have disclosed no relevant financial relationships.

Author affiliations: Centers for Disease Control and Prevention, Atlanta, Georgia, USA (K. Benedict, B.R. Jackson); Wisconsin Department of Health Services, Madison, Wisconsin, USA (S. Gibbons-Burgener, A. Kocharian); Minnesota Department of Health, St. Paul, Minnesota, USA (M. Ireland); Arkansas
Department of Health, Little Rock, Arkansas, USA (L. Rothfeldt); Louisiana Department of Health, Lafayette, Louisiana, USA (N. Christophe); Michigan Department of Health and Human Services, Lansing, Michigan, USA (K. Signs)

DOI: https://doi.org/10.3201/eid2704.204078 
Blastomycosis is caused by inhalation of Blastomyces spp. fungi. Limited data are available on the incidence and geographic range of blastomycosis in the United States. To better characterize its epidemiologic features, we analyzed combined surveillance data from the 5 states in which blastomycosis is reportable: Arkansas, Louisiana, Michigan, Minnesota, and Wisconsin. Surveillance identified 4,441 cases during 1987-2018, a mean of 192 cases per year. The mean annual incidence was $<1$ case $/ 100,000$ population in most areas but $>20$ cases $/ 100,000$ population in some northern counties of Wisconsin. Median patient age was 46 years, 2,892 (65\%) patients were male, 1,662 (57\%) were hospitalized, and $278(8 \%)$ died. The median time from symptom onset to diagnosis was 33 days. The severity of illness and diagnostic delays suggest that surveillance underestimates the true number of cases. More in-depth surveillance in additional states could elucidate blastomycosis incidence and inform efforts to increase awareness.

$\mathrm{B}$ lastomycosis is a fungal infection caused primarily by inhalation of the environmental fungi Blastomyces dermatitidis and B. gilchristii. The incubation period varies from 2 to 15 weeks, and the clinical spectrum ranges from asymptomatic to life-threatening infections involving acute respiratory distress syndrome or extrapulmonary dissemination $(1,2)$. Most identified cases involve pulmonary infection that manifests similarly to other causes of pneumonia $(1,2)$. The clinical similarities between blastomycosis and other pulmonary infections often result in diagnostic delays and unnecessary empiric antimicrobial drug treatment for suspected bacterial pneumonia (3). Because acute illnesses can self-resolve before diagnosis, and because physician awareness of this generally uncommon disease probably is low in most parts of the United States, many blastomycosis cases likely go undetected.

In the United States, most blastomycosis cases are thought to occur in the midwestern, south-central, and southeastern states, in areas surrounding the Ohio and Mississippi River valleys, the Great Lakes, and the Saint Lawrence River. Cases also occur outside these regions, indicating that the infection's true range is broader than generally appreciated $(4,5)$. Blastomyces spp. appear to have an affinity for moist soil and decomposing plant matter, but much remains unknown about its precise environmental niche $(6,7)$. The fungus is difficult to isolate from the environment, making investigation of potential sources challenging.

Public health surveillance for blastomycosis in the United States is limited because it is currently reportable in only 5 US states: Arkansas, Louisiana, Michigan, Minnesota, and Wisconsin. Blastomycosis is not nationally notifiable, so the Centers for Disease Control and Prevention does not routinely receive case reports from states where it is reportable. Nevertheless, surveillance data represent some of the most comprehensive information about blastomycosis. Before the Council of State and Territorial Epidemiologists (CSTE) approved a standardized surveillance case definition in 2019 (8), state health departments used different case definitions (Appendix, https: / / wwwnc.cdc.gov / EID / article / 27 / 4/204078-App1.pdf). However, state surveillance generally collected similar demographic, clinical, and laboratory data elements, enabling comparisons across states. We summarized available blastomycosis surveillance data to assess the overall burden of disease, geographic patterns and temporal trends, and factors associated with poor clinical outcomes.

\section{Methods}

We combined deidentified data on blastomycosis cases reported in Arkansas during January 1995May 2018, Louisiana during January 1987-October 2018, Michigan during January 2007-December 2017, Minnesota during January 1999-December 2018, and Wisconsin during January 1990-December 2017. We also used the Louisiana Hospital Inpatient Discharge Database to identify additional cases among hospitalized patients in Louisiana during 1999-2014.

We included data elements that were collected by $\geq 3$ states. We considered event date as the earliest date associated with the case; for example, symptom onset, or first healthcare visit, laboratory test order, or public health report. We considered all laboratory tests recorded as positive for blastomycosis to be positive, even without an explicitly stated qualitative or quantitative result. Negative blastomycosis test results were not routinely available; therefore, we did not include these in the analysis.

We used patients' state and county of residence to calculate annual state-specific incidence and countylevel mean annual incidence per 100,000 persons by using yearly population estimates from the US Census Bureau, Population Division, Vintage 2015 Special Tabulation (https://www.census.gov). We used $\chi^{2}$, Fisher exact, and $t$-tests to identify factors independently associated with hospitalization or death, the Cochran-Armitage test for trends in the proportion of patients who were hospitalized or died, and negative binomial regression to assess incidence trends, and we considered $\mathrm{p}<0.05$ statistically significant. We also compared demographic features and outcomes among cases associated with outbreaks (outbreak cases) and those not associated with outbreaks 
(nonoutbreak cases) for Minnesota and Wisconsin, the 2 states that reported outbreaks during the surveillance periods we examined. Human subjects review by the Centers for Disease Control and Prevention determined this project to be consistent with nonresearch public health surveillance.

\section{Results}

\section{Descriptive Analysis}

Data were available for 4,441 cases: 348 from Arkansas, 296 from Louisiana, 186 from Michigan, 671 from Minnesota, and 2,904 from Wisconsin. Most (2,892 [65\%]) patients were male, and the median age was 46 years (range $0-97$, interquartile range [IQR] 31-59) (Table 1). Most $(64 \%, \mathrm{n}=2,778)$ cases were among persons of White race, $17 \%$ (740) were among persons of unknown race, $9 \%$ (406) were among persons of Black or African American races, and 5\% (193) were among Asian, Native Hawaiian, or other Pacific Islander races. Most (2,828 [71\%]) patients were not Hispanic or Latino; ethnicity was unknown for 1,015 (26\%) patients.

Symptom data were available for 2,005 patients from Michigan, Minnesota, and Wisconsin beginning in 2005. The most common symptoms were cough in $79 \%$ (range by state $51 \%-83 \%$ ) of patients, fever in $61 \%$ (range by state $38 \%-69 \%$ ), shortness of breath in $55 \%$ (range by state $44 \%-85 \%$ ), and weight loss in $54 \%$ (range by state $29 \%-62 \%$ ).

Among 2,912 patients with hospitalization data, $57 \%(1,662)$ were hospitalized. The median length of hospitalization was 7 days (range 1-379 days, IQR 4-15 days; $\mathrm{n}=1,231)$. Among 3,385 patients with mortality data, 278 (8\%) died. The proportion of hospitalized patients did not change significantly during 2007-2017 ( $p=0.252)$, but the proportion of patients who died increased from $9.9 \%$ to $12.4 \%$ ( $p=0.017$ ).

Data on positive blastomycosis laboratory tests were consistently available from Arkansas, Michigan, and Minnesota (Table 2). Among 1,241 reported cases from the 3 states, the most common test types were culture among $835(67 \%)$ cases and microscopy among $333(27 \%)$ cases. Less commonly reported tests included positive antigen tests for $206(17 \%)$ cases and antibody tests for $59(5 \%)$ cases.

Among 777 patients with available data, the median time from symptom onset to diagnosis was 33 days (range 1-2,996 days; IQR 16-75 days). We did not observe clear seasonal patterns by event month. Minnesota had 32 (5\%) outbreak cases and Wisconsin had 181 (6\%) outbreak cases. Outbreak cases were more frequent among younger persons (median age 25 years) than nonoutbreak cases (median age 45 years; $p=0.0092)$. Outbreak cases also more often occurred among female persons $(41 \%$ vs. $34 \%$ of nonoutbreak cases; $\mathrm{p}=0.0365$ ) and non-White persons $(28 \%$ vs. $19 \%$ of nonoutbreak cases; $p=0.002)$. In addition, persons with outbreak cases were less likely to be hospitalized ( $45 \%$ vs. $58 \%$ of nonoutbreak cases; $\mathrm{p}=0.003)$ or to have died ( $2 \%$ vs. $9 \%$ of nonoutbreak cases; $\mathrm{p}=0.001$ ).

\section{Bivariable Analysis}

Age; female sex; non-White race; and positive antigen, culture, and microscopy tests had statistically significant associations with hospitalization (Table 3). The median age among hospitalized patients was 46 years compared with 44 years for nonhospitalized patients $(p=0.015)$. Female patients were more likely to be hospitalized (relative risk [RR] 1.13; 95\% CI 1.061.21) than male patients. Persons of non-White races were more likely to be hospitalized (RR 1.13; $95 \%$ CI 1.05-1.21) than persons of White race. Patients with positive antigen tests (RR 1.25; 95\% CI 1.13-1.37), positive culture (RR 1.28; 95\% CI 1.20-1.36), and positive microscopy (RR 1.32; 95\% CI 1.23-1.43) were more likely to be hospitalized than patients without positive results for those laboratory tests. Factors significantly associated with death were older age (median 61 years vs. 44 years; $\mathrm{p}<0.001)$ and positive microscopy test (RR 1.76; 95\% CI 1.34-2.38).

\begin{tabular}{lc}
\hline Table 1. Patient characteristics of blastomycosis cases reported \\
to public health, Arkansas, Louisiana, Michigan, \\
Wisconsin, USA, 1987-2018* \\
\hline Characteristic & Value \\
\hline Median age, $\mathrm{y}$ (range; IQR), $\mathrm{n}=4,390$ & $46(0-97 ; 31-59)$ \\
Mean age, $\mathrm{y}, \mathrm{n}=4,390$ & 45.3 \\
\hline Sex, $\mathrm{n}=4,441$ & \\
$\mathrm{M}$ & $2,892(65.1)$ \\
$\mathrm{F}$ & $1,533(34.5)$ \\
Unknown & $16(0.4)$ \\
\hline Race, $\mathrm{n}=4,316$ & \\
White & $2,778(64.4)$ \\
Black or African American & $406(9.4)$ \\
Asian, Native Hawaiian, other Pacific & $193(4.5)$ \\
Islander & \\
American Indian or Alaska Native & $152(3.5)$ \\
Other or multiple races & $47(1.1)$ \\
Unknown & $740(17.2)$ \\
\hline Ethnicity, $\mathrm{n}=3,984$ & \\
Not Hispanic or Latino & $2,828(71.0)$ \\
Hispanic or Latino & $141(3.5)$ \\
Unknown & $1,015(25.5)$ \\
\hline Hospitalized, $\mathrm{n}=2,912$ & \\
Y & $1,662(57.1)$ \\
$\mathrm{N}$ & $1,250(42.9)$ \\
\hline Died, $\mathrm{n}=3,385$ & $278(8.2)$ \\
Y & $3,107(91.8)$ \\
$\mathrm{N}$ &
\end{tabular}




\section{Incidence}

During years for which data were available from all 5 states, 2007-2017, surveillance detected 2,111 cases, a mean of 192 cases per year. In Arkansas, incidence declined from 1.3 cases/100,000 population in 1995 to 0.4 cases $/ 100,000$ population in 2017 ( $p<0.001$ ) (Figure 1). Incidence was stable during each state's surveillance period in Louisiana, Michigan, and Minnesota. Mean annual incidence was 0.2 cases/100,000 population in Louisiana, 0.2 cases/100,000 population in Michigan, and 0.6 cases/100,000 population in Minnesota. In Wisconsin, incidence peaked at $>3$ cases/100,000 population during 2006, 2010, and 2015. Mean annual county-level incidence in Wisconsin was highest in Menominee (42.1 cases/100,000 population), Lincoln (28.4 cases/100,000 population), and Vilas (26.5/100,000 population) counties (Figure 2).

\section{Discussion}

We summarize blastomycosis surveillance data from 5 states and provide a broad update on the basic epidemiology of this enigmatic and underrecognized disease. Many patients experienced severe outcomes and diagnostic delays. Our results show that blastomycosis is underdetected, even in states where it is reportable, and that more standardized and in-depth surveillance, ideally in additional states, would help public health professionals better identify highest-risk groups and emerging areas for targeted prevention messaging.

Blastomycosis often results in severe illness, even in previously healthy persons (9), but this observation might be influenced by underdetection of asymptomatic or milder, self-resolving disease. The high hospitalization rate of $57 \%$ noted in this analysis demonstrates that blastomycosis surveillance detects severe cases, which is typical for passive disease surveillance. We found an annual mean of $<200$ cases/ year; a hospitalization rate of $57 \%$ suggests that $\approx 110$ patients are hospitalized each year from states where blastomycosis is reportable. In contrast, $\approx 1,000$ blastomycosis-associated hospitalizations occur nationwide $(10,11)$, showing that the limited surveillance likely underdetects cases nationally.
Table 2. Positive laboratory tests among 1,241 blastomycosis cases reported to public health, Arkansas, Michigan, and Minnesota, United States, 1995-2018

\begin{tabular}{lc}
\hline Test type & No. $(\%)$ \\
\hline Antibody & $59(4.8)$ \\
Immunodiffusion & $18(1.5)$ \\
Complement fixation & $7(0.6)$ \\
Enzyme immunoassay & $30(2.4)$ \\
Unspecified antibody test & $17(1.4)$ \\
\hline Antigen & $206(16.6)$ \\
\hline Confirmatory test & $965(77.8)$ \\
Culture & $835(67.3)$ \\
Microscopy & $333(26.8)$ \\
DNA probe & $40(3.2)$ \\
PCR & $2(0.2)$ \\
Unspecified test type & $166(13.4)$ \\
\hline Specimen type & \\
Culture & $769(100)$ \\
Bronchial specimen & $372(48.4)$ \\
Sputum & $180(23.4)$ \\
Other tissue besides lung & $121(15.7)$ \\
Lung tissue & $21(2.7)$ \\
Multiple specimen types & $14(1.8)$ \\
Other & $61(7.9)$ \\
Microscopy & $342(100)$ \\
Bronchoalveolar lavage & $110(32.2)$ \\
Sputum & $78(22.8)$ \\
Other tissue besides lung & $52(15.2)$ \\
Lung tissue & $47(13.7)$ \\
Multiple specimen types & $24(7.0)$ \\
Other & $31(9.1)$ \\
\hline${ }^{*}$ Includes smear, histopathology, and unspecified microscopy tests. \\
\hline
\end{tabular}

The average time of $>1$ month from symptom onset to diagnosis indicates delays in seeking healthcare, delays in diagnosis, or both. This time interval is consistent with a previous report describing a median of 23 days between examination at a healthcare facility and a median of 2.5 courses of antibacterial medications for presumed bacterial infection before pulmonary blastomycosis was correctly diagnosed (3). Earlier diagnosis might reduce unnecessary antibacterial drug use, time, and resources invested in searching for alternative diagnoses and could potentially improve patient outcomes. Therefore, greater public and provider education about blastomycosis is needed, especially in areas where blastomycosis is less commonly recognized.

The high proportion of patients with positive confirmatory laboratory tests, such as culture and

\begin{tabular}{|c|c|c|c|c|}
\hline \multirow[b]{2}{*}{ Characteristic } & \multicolumn{2}{|c|}{ Hospitalization } & \multicolumn{2}{|c|}{ Death } \\
\hline & RR (95\% Cl) & $p$ value & RR (95\% Cl) & $p$ value \\
\hline Older age & NA & 0.015 & NA & $<0.001$ \\
\hline Female sex & $1.13(1.05-1.21)$ & $<0.001$ & $1.05(0.83-1.33)$ & 0.681 \\
\hline Non-White race & $1.13(1.05-1.21)$ & 0.002 & $1.08(0.82-1.42)$ & 0.588 \\
\hline Antigen test $†$ & 1.25 (1.13-1.37) & $<0.001$ & $1.27(0.84-1.92)$ & 0.255 \\
\hline Culture† & $1.28(1.20-1.36)$ & $<0.001$ & $1.02(0.79-1.33)$ & 0.864 \\
\hline Microscopy† & $1.32(1.23-1.43)$ & $<0.001$ & $1.76(1.34-2.38)$ & $<0.001$ \\
\hline
\end{tabular}

*NA, not applicable; RR, relative risk

†Arkansas, Michigan, and Minnesota only. 


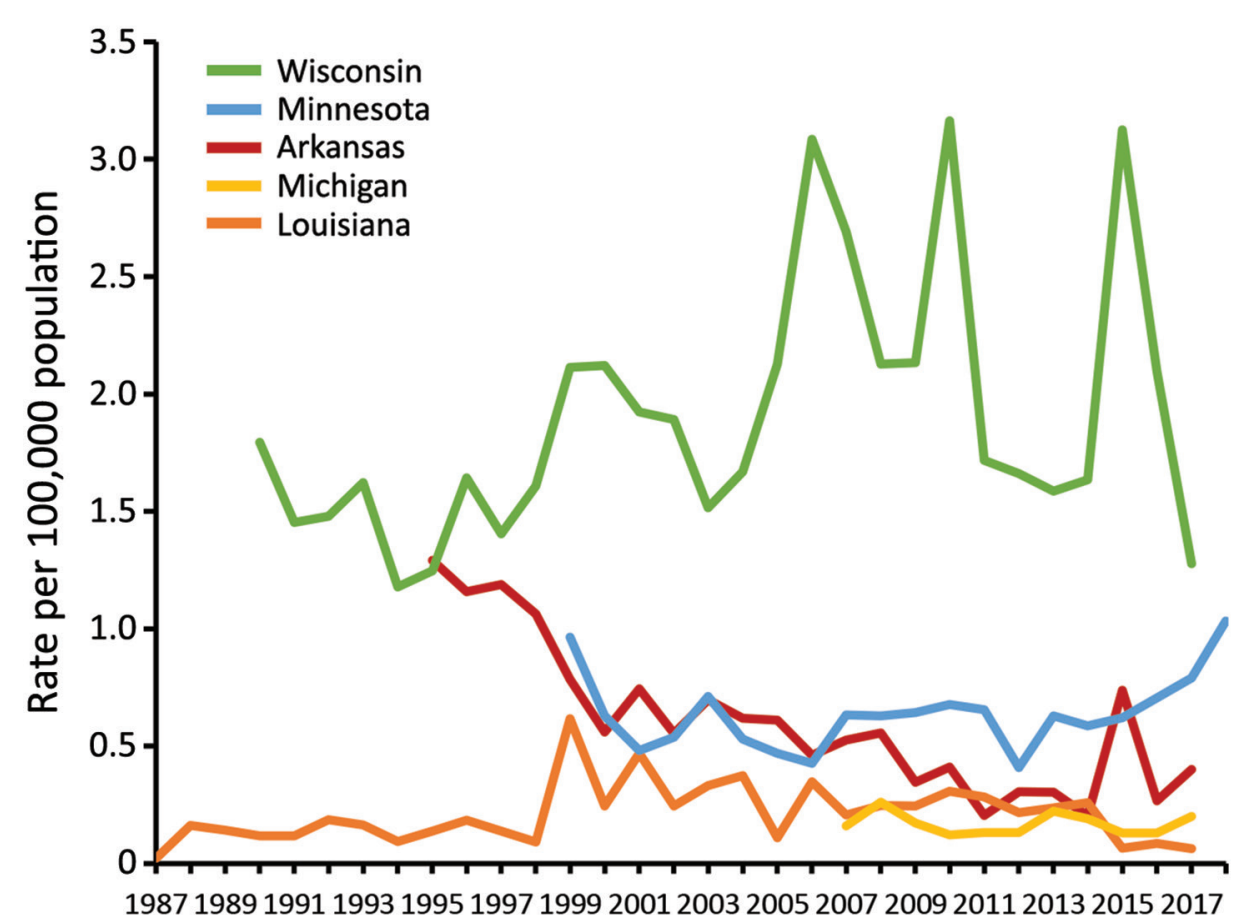

Figure 1. Annual state-specific incidence (no. cases/100,000 population) among 5 states in which blastomycosis is reportable, United States, 1987-2018. Cases reported during 2018 in Arkansas and Louisiana were excluded because data were not available for the entire year.

microscopy, likely reflects detection of more severe cases because serologic tests for blastomycosis offer only presumptive evidence of infection (12), and serologic tests were not included in most states' case definitions (Appendix). The associations between older age and confirmatory test types with hospitalization point to severe illness, and are unsurprising; however, why women were more likely to be hospitalized is unclear but could be related to delayed diagnosis or underdiagnosis of less severe disease in women. More blastomycosis hospitalizations typically occur among men $(10,13)$, although a recent study found female sex was independently associated with death in blastomycosis patients with acute respiratory distress syndrome (14). The increased risk for hospitalization among persons of non-White races lends further evidence to the existence of blastomycosis-related health disparities, as previously suspected (15-17). Further studies could help determine whether these differences are related to genetic predisposition (18), involvement in outdoor activities resulting in exposures to Blastomyces, or access to medical care (19).

Reliance on often invasive and time-consuming tests such as culture and microscopy for diagnosis likely is a key factor in underdiagnosis of blastomycosis because these tests might not be ordered until tests for other diseases have been negative. Accordingly, most specimen types in our analysis were from bronchoalveolar lavage and lung and other tissue, which likely required biopsy. Given the prolonged time to diagnosis we identified, improved noninvasive diagnostic methods with high sensitivity and specificity for blastomycosis are needed for earlier and more frequent testing, which could prevent hospitalizations and deaths.

Consistent with previous reports, Wisconsin had the highest number of cases and incidence of the 5 states where blastomycosis is reportable, with mean annual incidence in several northern counties $>20$ cases $/ 100,000$ population. Peaks in incidence in Wisconsin corresponded to a known outbreak at a yard waste site in 2006 (20), an outbreak likely associated with multiple sources in 2010 (21), and an outbreak linked to recreational tubing on the Little Wolf River in 2015 (22). For case-patients in these outbreaks, younger age and higher likelihood of being non-White was consistent with our findings $(20,21)$. In addition, the finding that patients with outbreak-associated cases had less severe outcomes could reflect detection of milder cases through enhanced case detection efforts during outbreak investigations. However, outbreaks comprised $<6 \%$ of cases overall, suggesting that most cases occur sporadically, which also is true for histoplasmosis and coccidioidomycosis. Of note, most of northern Wisconsin is rich in soils classified as spodosols, which are characterized by high concentrations of organic matter in coarse, often sandy, particles (23). Blastomyces spp. are thought to dwell primarily in organic-rich soils. However, spodosols 
also occur widely in northern Michigan, where disease incidence was not elevated, and are less common in northern Minnesota, where incidence was higher. Further study, including the role of soil types, could elucidate the natural habitat of these fungi.

For most states in this analysis, the relatively stable incidence and hospitalization rates over time were consistent with a previous analysis of blastomycosis-related hospitalizations during 2000-2011 (10). Another study found a decline in blastomycosis-associated deaths nationwide during 1990-2010 (15); the reasons for the increase in deaths we observed during 2007-2017 are unclear but could reflect improvements in case follow-up, a decline in reporting of less severe cases, or other surveillance changes over time.

The limitations of our study include that pooling surveillance data based on different blastomycosis case definitions is fundamentally problematic; however, few other data sources would enable analyses of thousands of cases, which is helpful for studying this uncommon disease. Furthermore, some states' case definitions changed over time. Although blastomycosis was reportable in each state during the years included in this analysis, Arkansas did not have a formal case definition, and Michigan did not have one until 2012. Wisconsin classified all cases as confirmed until September 2015, when their case definition changed to include confirmed and probable case classifications; for outbreaks in Wisconsin, a positive serologic blastomycosis test plus an epidemiologic link was sufficient to be considered a case. Moving forward, the standardized blastomycosis case definition from the Council of State and Territorial Epidemiologists will enable more robust comparisons between states and stratification of confirmed and probable cases.

Combining data from different times in each state is an additional potential limitation. Some states'

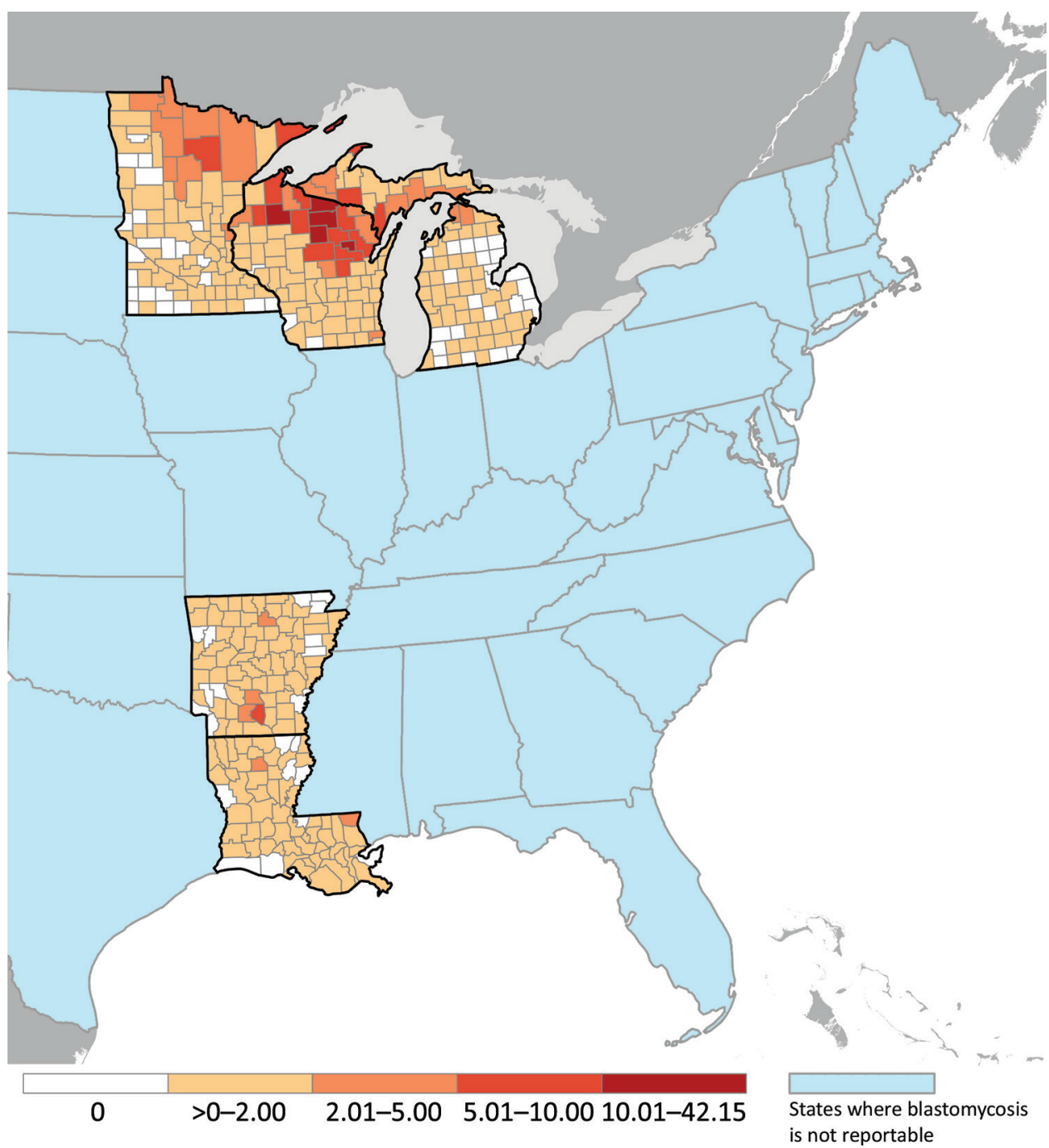

Figure 2. Mean annual county-specific incidence (no. cases $/ 100,000$ population) among 5 states in which blastomycosis is reportable, United States, 1987-2018. Cases reported during 2018 in Arkansas and Louisiana were excluded because data were not available for the entire year. 
surveillance systems underwent changes during the analysis period; for example, data elements were added or removed, resulting in inconsistent denominators in the pooled analysis. For certain variables, such as race and ethnicity, missing data or values of "unknown" were common and demonstrate that information can be challenging to obtain because substantial time and resources often are needed to conduct case investigations (24). Data about environmental exposures, immunocompromised status, body site of infection, occupation, illness duration, and treatment were not available consistently from every state. Wisconsin and Minnesota conducted extensive follow-up on cases $(19,25)$, providing deeper insight into statespecific features of blastomycosis. Collecting these types of data in a standardized way in additional states could help identify high-risk populations and activities and help inform prevention efforts.

In summary, blastomycosis remains a rarely reported but severe disease in most areas where it is under public health surveillance. Our findings indicate that blastomycosis likely is underdetected. Blastomycosis also can occur in areas outside those where it is commonly recognized (4) and might be emerging in new areas, such as east-central New York (5). Surveillance for blastomycosis in more areas and collection of more standardized, detailed data could help identify emerging geographic hotspots or clusters, new risk factors, and other epidemiologic patterns. Increased awareness among healthcare providers and the public could lead to faster diagnosis and treatment for blastomycosis patients.

\section{Acknowledgments}

We thank Jose Antonio Serrano and Stephanie McCracken for contributions to early study design and for coordinating blastomycosis data access; Racheal Odom for blastomycosis data collection; Jeff P. Davis (Wisconsin State Epidemiologist 1978-2018) for his tremendous contribution to the study of blastomycosis epidemiology and its surveillance; Nina D. Dutton for assistance with Figure 2; and Richard Bishop for coordinating access to US Census data.

\section{About the Author}

Ms. Benedict is an epidemiologist in the Mycotic Diseases Branch, Division of Foodborne, Waterborne, and Environmental Diseases, National Center for Emerging and Zoonotic Infectious Diseases, Centers for Disease Control and Prevention, Atlanta, Georgia, USA. Her research interests include the epidemiology and prevention of fungal infections.

\section{References}

1. Chapman SW, Dismukes WE, Proia LA, Bradsher RW, Pappas PG, Threlkeld MG, et al.; Infectious Diseases Society of America. Clinical practice guidelines for the management of blastomycosis: 2008 update by the Infectious Diseases Society of America. Clin Infect Dis. 2008;46:1801-12. https:// doi.org/10.1086/588300

2. McBride JA, Gauthier GM, Klein BS. Clinical manifestations and treatment of blastomycosis. Clin Chest Med. 2017;38:435-49. https://doi.org/10.1016/j.ccm.2017.04.006

3. Alpern JD, Bahr NC, Vazquez-Benitez G, Boulware DR, Sellman JS, Sarosi GA. Diagnostic delay and antibiotic overuse in acute pulmonary blastomycosis. Open Forum Infect Dis. 2016;3:ofw078. https:/ / doi.org/10.1093/ofid/ ofw078

4. Benedict K, Thompson GR III, Deresinski S, Chiller T. Mycotic infections acquired outside areas of known endemicity, United States. Emerg Infect Dis. 2015;21:1935-41. https://doi.org/10.3201/eid2111.141950

5. McDonald R, Dufort E, Jackson BR, Tobin EH, Newman A, Benedict K, et al. Notes from the field: blastomycosis cases occurring outside of regions with known endemicity New York, 2007-2017. MMWR Morb Mortal Wkly Rep. 2018;67:1077-8. https://doi.org/10.15585/mmwr. mm6738a8

6. Reed KD, Meece JK, Archer JR, Peterson AT. Ecologic niche modeling of Blastomyces dermatitidis in Wisconsin. PLoS One. 2008;3:e2034. https:/ / doi.org/10.1371/journal.pone.0002034

7. McTaggart LR, Brown EM, Richardson SE. Phylogeographic analysis of Blastomyces dermatitidis and Blastomyces gilchristii reveals an association with North American freshwater drainage basins. PLoS One. 2016;11:e0159396. https://doi.org/10.1371/journal.pone.0159396

8. Council of State and Territorial Epidemiologists. Standardized surveillance case definition for blastomycosis 2019 [cited 2020 Mar 12]. https:/ / cdn.ymaws.com/www.cste.org/resource/ resmgr/2019ps/final/19-ID-02_Blastomycosis_final.pdf

9. McBride JA, Sterkel AK, Matkovic E, Broman AT, Gibbons-Burgener SN, Gauthier GM. Clinical manifestations and outcomes in immunocompetent and immunocompromised patients with blastomycosis. Clin Infect Dis. 2020;ciaa276. https:// doi.org/10.1093/cid/ciaa276

10. Seitz AE, Younes N, Steiner CA, Prevots DR. Incidence and trends of blastomycosis-associated hospitalizations in the United States. PLoS One. 2014;9:e105466. https:/ / doi.org/ 10.1371/journal.pone.0105466

11. Benedict K, Jackson BR, Chiller T, Beer KD. Estimation of direct healthcare costs of fungal diseases in the United States. Clin Infect Dis. 2019;68:1791-7. https:/ / doi.org/10.1093/ cid/ciy776

12. Saccente M, Woods GL. Clinical and laboratory update on blastomycosis. Clin Microbiol Rev. 2010;23:367-81. https:/ / doi.org/10.1128/CMR.00056-09

13. Chu JH, Feudtner C, Heydon K, Walsh TJ, Zaoutis TE. Hospitalizations for endemic mycoses: a populationbased national study. Clin Infect Dis. 2006;42:822-5. https://doi.org/10.1086/500405

14. Rush B, Lother S, Paunovic B, Mooney O, Kumar A. Outcomes with severe blastomycosis and respiratory failure in the United States. Clin Infect Dis. 2020;ciaa294. https://doi.org/10.1093/cid/ciaa294

15. Khuu D, Shafir S, Bristow B, Sorvillo F. Blastomycosis mortality rates, United States, 1990-2010. Emerg Infect Dis. 2014;20:1789-94. https://doi.org/10.3201/eid2011.131175

16. Lemos LB, Guo M, Baliga M. Blastomycosis: organ involvement and etiologic diagnosis. A review of 123 
patients from Mississippi. Ann Diagn Pathol. 2000;4:391-406. https://doi.org/10.1053/adpa.2000.20755

17. Dworkin MS, Duckro AN, Proia L, Semel JD, Huhn G. The epidemiology of blastomycosis in Illinois and factors associated with death. Clin Infect Dis. 2005;41:e107-11. https://doi.org/10.1086/498152

18. Merkhofer RM Jr, O'Neill MB, Xiong D, Hernandez-Santos N, Dobson H, Fites JS, et al. Investigation of genetic susceptibility to blastomycosis reveals interleukin- 6 as a potential susceptibility locus. MBio. 2019;10:e1224-19. https:/ / doi.org/10.1128/mBio.01224-19

19. Gibbons-Burgener SN, Dieckman JL, Davis JP. Epidemiology of sporadic blastomycosis in Wisconsin, 2011-2015. Presented at: CSTE 2017 Annual Conference; Boise, Idaho, USA; June 4-8, 2017.

20. Pfister JR, Archer JR, Hersil S, Boers T, Reed KD, Meece JK, et al. Non-rural point source blastomycosis outbreak near a yard waste collection site. Clin Med Res. 2011;9:57-65. https:/ / doi.org/10.3121/cmr.2010.958

21. Roy M, Benedict K, Deak E, Kirby MA, McNiel JT, Sickler CJ, et al. A large community outbreak of blastomycosis in Wisconsin with geographic and ethnic clustering. Clin Infect Dis. 2013;57:655-62. https:// doi.org/10.1093/cid/cit366
22. Koske SE, Kocharian A, Kazmierczak JJ, Gibbons-Burgener SN, Dieckman JL, Klos RF, et al. Investigation of a large outbreak of blastomycosis caused by Blastomyces gilchristii among recreational river tubers, Wisconsin, 2015. Presented at: CSTE 2017 Annual Conference; Boise, Idaho, USA; June 4-8, 2017.

23. United States Department of Agriculture, Natural Resources Conservation Service. Spodosols map [cited 2020 Apr 22]. https://www.nrcs.usda.gov/wps/portal/nrcs/detail/soils/ survey/class/maps/?cid=nrcs142p2_053608

24. McCracken S, Signs K, Stobierski M. Evaluating blastomycosis disease reporting in Michigan's disease surveillance system. Presented at: 2018 CSTE Annual Conference; West Palm Beach, Florida, USA; June 10-14, 2018.

25. Ireland M, Klumb C, Smith K, Scheftel J. Blastomycosis in Minnesota, USA, 1999-2018. Emerg Infect Dis J. 2020;26:86675. https:/ / doi.org/10.3201/eid2605.191074

Address for correspondence: Kaitlin Benedict, Centers for Disease Control and Prevention, 1600 Clifton Road NE, Mailstop H24-9, Atlanta, GA 30329-4027, USA; email: jsy8@cdc.gov

\title{
etymologia
}

\section{Treponema [trep"o-ne'mə]}

\author{
Fabio C. Pogliani, ${ }^{1}$ Rüdiger D. Ollhoff ${ }^{1}$
}

From the Greek trepo (rotate, turn) and ne ${ }^{-}$ma (thread), Treponema is a genus of - gram-negative, anaerobic or microaerophilic bacteria. They are spiral-shaped and have flagella, which extend from motors at the pole, producing undulating movement through fluids, enabling tissue invasion and dissemination. In 1905, microbiologist Fritz Richard Schaudinn and dermatologist Paul Erich Hoffmann described Treponema pallidum subsp. pallidum as Spirochaeta pallida from a fresh human vulvar lesion.

Treponema spp. can invade the epidermis and oral, intestinal, and genital mucosa of humans and animals. They cause human diseases, such as syphilis, yaws, pinta, and bejel, and animal diseases, such as digital dermatitis. T. phagedenis, T. pedis, and T. medium infect mainly cattle. T. paraluiscuniculi can cause syphilis in rabbits.

Most Treponema spp. are not cultivable, except for T. pallidum subsp. pallidum and T. phagedenis. T. pallidum subsp. pallidum causative syphilis is a reemerging disease in industrialized countries. Digital dermatitis, a polytreponemal disease, is considered to be the major infectious claw disease in cattle worldwide.

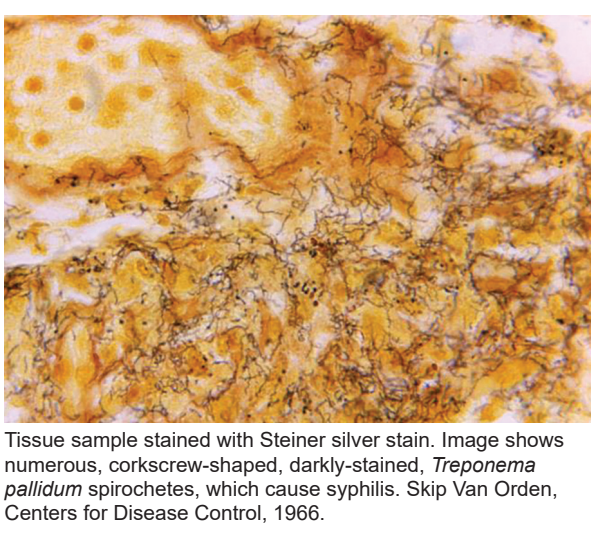

Address for correspondence: Rüdiger D. Ollhoff, Programa de Pós-Graduação em Ciência Animal da Pontifícia Universidade Católica do Paraná, Rua Imaculada Conceição, 1155 Prado Velho, Curitiba 80215 901, Paraná, Brazil; email: daniel.ollhoff@pucpr.br

\section{Sources}

1. Dorland's illustrated medical dictionary. 32nd ed. Philadelphia: Elsevier Saunders; 2012.

2. Edmondson DG, Hu B, Norris SJ. Long-term in vitro culture of the syphilis spirochete Treponema pallidum subsp. pallidum. MBio. 2018;9:e01153. https://doi.org/10.1128/ mBio.01153-18

3. Nally JE, Hornsby RL, Alt DP, Whitelegge JP. Phenotypic and proteomic characterization of treponemes associated with bovine digital dermatitis. Vet Microbiol.
2019;235:35-42. https://doi.org/10.1016/j.vetmic. 2019.05.023

4. Oriel JD. The scars of Venus: a history of venereology. London: Springer-Verlag; 1994.

5. Šmajs D, Zobaníková M, Strouhal M, Čejková D, Dugan-Rocha S, Pospíšilová P, et al. Complete genome sequence of Treponema paraluiscuniculi, strain Cuniculi A: the loss of infectivity to humans is associated with genome decay. PLoS One. 2011;6:e20415. https:/ / doi.org/10.1371/ journal.pone.0020415 